

\title{
Nitrogen diffusion through cementite layers
}

\begin{tabular}{|c|c|}
\hline Journal: & Philosophical Magazine \& Philosophical Magazine Letters \\
\hline Manuscript ID: & TPHM-09-Jul-0301.R1 \\
\hline Journal Selection: & Philosophical Magazine \\
\hline $\begin{array}{r}\text { Date Submitted by the } \\
\text { Author: }\end{array}$ & 20-Aug-2009 \\
\hline Complete List of Authors: & $\begin{array}{l}\text { Nikolussi, Marc; Max Planck Institute for Metals Research,, } \\
\text { Department Mittemeijer } \\
\text { Leineweber, Andreas; Max Planck Institute for Metals Research, } \\
\text { Department Mittemeijer } \\
\text { Mittemeijer, Eric Jan; Max Planck Institute for Metals Research, } \\
\text { Prof. Dr Ir. E.J. Mittemeijer }\end{array}$ \\
\hline Keywords: & carbides, diffusion, nitrides, thermodynamics \\
\hline Keywords (user supplied): & cementite, nitrocarburising, activation energy \\
\hline
\end{tabular}

\section{s scholarONE" \\ Manuscript Central}




\title{
Nitrogen diffusion through cementite layers
}

Marc Nikolussi, Andreas Leineweber, Eric Jan Mittemeijer

Max Planck Institute for Metals Research, Heisenbergstrasse 3, D-70569 Stuttgart, Germany

\begin{abstract}
Massive cementite layers with a time-dependent thickness were grown on ferrite substrates by nitrocarburising in a dedicated $\mathrm{NH}_{3} / \mathrm{H}_{2} / \mathrm{CO} / \mathrm{N}_{2}$ containing gas atmosphere at $783 \mathrm{~K}, 823 \mathrm{~K}$ and $843 \mathrm{~K}$. Nitrogen diffusion through the cementite layer into the ferrite substrate took place in conjunction with growth of the cementite layer; a significant, i.e. measurable solubility of nitrogen in cementite was not observed. The nitrogen concentration-depth profiles in the substrate, underneath the growing cementite layer, were quantitatively determined using a calibrated microhardness-measurement technique. The nitrogen concentration-depth profiles were simulated on the basis of a model using an implicit finite-difference method. The simulation yielded values for the diffusivity of nitrogen through cementite, including the activation energy.
\end{abstract}

Keywords: cementite; nitrogen diffusion; activation energy; nitrocarburising; nitriding 


\section{Introduction}

The corrosion and wear resistances of iron-based workpieces as well as the fatigue endurance can be improved pronouncedly by thermochemical heat treatments such as nitriding and nitrocarburising which are of great technological importance [1, 2].

Gaseous nitriding and gaseous nitrocarburising are usually performed at temperatures between $773 \mathrm{~K}$ and $853 \mathrm{~K}$. Thus, the process temperature is located below the binary/ternary eutectoid temperature of the $\mathrm{Fe}-\mathrm{N} / \mathrm{Fe}-\mathrm{N}-\mathrm{C}$ solid solution $[3,4] . \quad$ The nitriding/nitrocarburising gas atmosphere provides nitrogen or nitrogen and carbon, which are taken up by the surface-region of the iron-based workpieces [5].

The incorporation of nitrogen or nitrogen and carbon results in (i) the formation of a compound layer (several $10 \mu \mathrm{m}$ thick) and/or (ii) the formation of a diffusion zone (several $100 \mu \mathrm{m}$ thick). The compound layer is responsible for a considerable enhancement of the corrosion and wear resistance. Depending on the treatment temperature, the pressure and the composition of the gas atmosphere, the compound layer can consist of different phases. Typically $\gamma^{\prime}-\mathrm{Fe}_{4} \mathrm{~N}_{1-y}$ and $\varepsilon-\mathrm{Fe}_{3}(\mathrm{~N}, \mathrm{C})_{1+x}$ are constituents of the compound layer [6] but also cementite can occur in the compound layer [7, 8]. The diffusion zone is responsible for a considerable enhancement of the fatigue endurance [9]. Nitrogen or nitrogen and carbon are dissolved (at the treatment temperature) as solid solution in the octahedral interstices of the iron bcc-lattice.

It was shown recently that, under certain conditions, also pure, massive cementite layers can form on the ferrite substrate [8]. These cementite layers have been investigated in detail with respect to their homogeneous cementite-phase microstructure, with respect to conditions for occurrence of additional (carbo)nitride phases and the corresponding phase equilibria as well as with respect to selected mechanical properties $[8,10,11,12,13,14]$.

In the presence of cementite compound layers it turns out that the nitrogen (and carbon) diffusion into the substrate is strongly decelerated; cementite acts as a diffusion barrier for 
nitrogen [15] and carbon [16]. Nonetheless, although nitrogen transport through cementite is decelerated, it is shown in this paper that a certain time-dependent amount of nitrogen is transported through the cementite into the ferrite substrate, leading to an increase of the nitrogen content in (and the hardness of) the ferrite substrate. The solubility of nitrogen in the ferrite is much higher than for carbon at the temperatures of interest $(783 \mathrm{~K}-843 \mathrm{~K})$, e.g. values of 0.29 at.- $\%$ for nitrogen vs. $\approx 0.012$ at.- $\%$ for carbon at $823 \mathrm{~K}$ are found in Ref. [17]. Furthermore, most of the carbon incorporated in the solid is used to build up the cementite layer, whereas nitrogen passes through the cementite layer to be dissolved in the ferrite.

The present work focuses on the diffusion of nitrogen through cementite. Hardnessdepth profile measurements in the ferrite substrate are used to determine the nitrogen concentration-depth profiles. A model is proposed that enables the simulation of such nitrogen concentration-depth profiles. On this basis, for the first time, information about the diffusivity of nitrogen through cementite, including the corresponding activation energy of nitrogen diffusion in cementite, is obtained.

\section{Experimental}

\subsection{Specimen preparation and gaseous nitriding/nitrocarburising}

Two differently produced types of specimens were investigated in this study: "Thick-plate" specimens for nitrocarburising experiments were produced by cold-rolling a ferrite cast rod (Alfa Aesar, 99.98 wt.-\% Fe) on both sides to a thickness of $1 \mathrm{~mm}$. From the resulting coldrolled sheet, rectangular pieces $(20 \mathrm{~mm} \times 25 \mathrm{~mm})$ were cut, ground, polished (final stage 1 $\mu \mathrm{m}$ diamond suspension) and cleaned ultrasonically in ethanol. "Thin-plate" specimens for nitriding experiments were produced by cutting from a $10 \mathrm{~cm} \times 10 \mathrm{~cm}$ iron sheet (Alfa Aesar, 99.98 wt.- $\% \mathrm{Fe}$ ) of $0.1 \mathrm{~mm}$ thickness rectangular pieces of $20 \mathrm{~mm} \times 25 \mathrm{~mm}$ which were ground, polished (final stage $1 \mu \mathrm{m}$ diamond suspension) and cleaned ultrasonically in ethanol. In order to remove the cold deformation both types of specimens were, prior to gaseous 
nitriding/nitrocarburising, recrystallised at $973 \mathrm{~K}$ for $2 \mathrm{~h}$ under a reductive hydrogen flow of $200 \mathrm{ml} \mathrm{min}{ }^{-1}$, polished (final stage $1 \mu \mathrm{m}$ diamond suspension) and cleaned ultrasonically in ethanol.

The nitriding/nitrocarburising facility had to ensure the desired gas environment and the desired temperature during treatment. Moreover, it was necessary to quench the specimens after treatment in order to retain the microstructure as at the treatment temperature. Thus, the nitriding/nitrocarburising facility was composed of a vertical quartz-tube furnace which was at its end equipped with a water (flushed with $\mathrm{N}_{2}$ ) container for quenching the specimens to room temperature. Using a quartz fibre, which, to realise quenching, can mechanically be destroyed after the nitriding/nitrocarburising treatment, the specimens prepared as described above were positioned in the middle of the quartz-tube furnace where the process temperature (controlled within $\pm 1 \mathrm{~K}$ ) prevailed.

Two types of treatments were conducted in the present work: (i) Nitrocarburising experiments to study nitrogen diffusion through growing cementite layers, and (ii) nitriding experiments to prepare specimens of homogeneous nitrogen content and without compound layer. For these experiments, ammonia (99.999 vol.-\%) as nitrogen supply, carbon monoxide (99.97 vol.-\%) as carbon supply, hydrogen (99.999 vol.-\%), and nitrogen (99.999 vol.-\%), as inert gas, were employed. Each gas flux was controlled by a separate mass-flow controller. An overall linear flow rate of $13.5 \mathrm{~mm} \mathrm{~s}^{-1}$ (calculated for the gas volume at room temperature) through the quartz retort (diameter $28 \mathrm{~mm}$ ) was maintained. Such a flow rate ensures that ammonia dissociation, which would change the composition of the gas atmosphere, can be neglected.

For gaseous nitrocarburising the gas atmosphere was composed of 13 vol.- $\% \mathrm{NH}_{3}, 58$ vol.- $\% \mathrm{H}_{2}$ (nitriding potential ${ }^{1} r_{\mathrm{N}}=0.3 \mathrm{~atm}^{-1 / 2}$ ), 20 vol.- $\% \mathrm{CO}$ and 9 vol.- $\% \mathrm{~N}_{2}$ (as inert gas).

\footnotetext{
${ }^{1}$ The chemical potential of nitrogen in the gas atmosphere can be related with the nitriding potential [18]. In the present work no carburising potential can be adjusted: the carburising potential for a gas atmosphere composed
} 
The experiments were performed at $T=783 \mathrm{~K}, 823 \mathrm{~K}$ and $843 \mathrm{~K}$, for treatment times of $0.5 \mathrm{~h}$, $2 \mathrm{~h}, 6 \mathrm{~h}, 14 \mathrm{~h}, 24 \mathrm{~h}$ and 48 h, leading always to massive cementite layers on ferrite substrates [8, 10] (cf. Fig. 1). For these experiments "thick-plate" specimens with a thickness of $1 \mathrm{~mm}$, produced as described above, were used. In fact, the $783 \mathrm{~K}$ and $843 \mathrm{~K}$ specimens are among those used in Ref. [10] to analyse the cementite-layer growth kinetics at the corresponding temperatures.

Gaseous nitriding experiments were performed at $823 \mathrm{~K}$ using different $\mathrm{NH}_{3} / \mathrm{H}_{2}$ containing gas atmospheres yielding different nitriding potentials ${ }^{1}$ (cf. Table 1). The applied experimental conditions ensured the formation of compound-layer free specimens in accordance with the Lehrer diagram [19]. Gaseous nitriding was performed for $42 \mathrm{~h}$ in order that the ferrite substrates were saturated with interstitial nitrogen with respect to the nitriding gas atmosphere. For these experiments "thin-plate" specimens with a thickness of $0.1 \mathrm{~mm}$, produced as described above, were used.

\subsection{Microstructural and hardness analysis}

The specimens after both the nitriding and the nitrocarburising experiments were cut into four pieces, used for optical microscopy, hardness measurements, carrier-gas hot extraction and X-ray diffraction (XRD), respectively.

For optical microscopy of and hardness measurements on specimen cross sections, the nitrocarburised specimens were covered with an electrodeposited protective nickel layer using a Watts bath $[6,20]$ at $333 \mathrm{~K}$. The protective nickel layer avoids mechanical damage at the surface of the metallographic cross sections and guarantees the required sharpness at the sample surface in the cross sections. All specimens (nitriding and nitrocarburising experiments) were embedded using a Struers LaboPress 3. Embedding was performed with 15

of $\mathrm{NH}_{3} / \mathrm{H}_{2} / \mathrm{CO} / \mathrm{N}_{2}$ is (hypothetically) infinite [8] although an "effective" carburising potential acts at the specimen surface [10]. 
$\mathrm{ml}$ Polyfast (Buehler $\mathrm{GmbH}$ ), a load of $15 \mathrm{kN}$, an annealing time of $5 \mathrm{~min}$ at $453 \mathrm{~K}$ and a cooling time of $3 \mathrm{~min}$ down to room temperature. After embedding, the specimens were ground, polished (final stage $1 \mu \mathrm{m}$ diamond suspension) and etched using 1 vol.-\% Nital containing 0.1 vol.- $\% \mathrm{HCl}$ [21]. In order to differentiate between the massive cementite layer and the ferrite substrate, the cross-sectional specimens were stained using either (i) an alkaline potassium permanganate solution $\left(1 \mathrm{~g} \mathrm{NaOH}, 1 \mathrm{~g} \mathrm{KOH}\right.$ and $4 \mathrm{~g} \mathrm{KMnO}_{4}$ per $100 \mathrm{ml}$ distilled water) at $328 \mathrm{~K}[8,22]$ of which the effect is similar to that of a Murakami solution $[6,22]$ or (ii) an alkaline sodium picrate solution $(25 \mathrm{~g} \mathrm{NaOH}$ and $2 \mathrm{~g}$ picric acid per $75 \mathrm{ml}$ distilled water) at room temperature [22]. In both cases the massive cementite layer gets, due to its high carbon content, severely stained. The ferrite substrate remains unstained and can therefore easily be distinguished from the cementite layer upon optical microscopy (Zeiss Axiophot microscope). By this type of staining it is also possible to differentiate between different nitride, carbonitride and carbide phases (also supported by electron back-scatter diffraction) in the compound layers, see e.g. Ref. 11, indicating that in the present work indeed were of pure cementite.

Hardness measurements (micro-Vickers) were performed with a Leica VMHT MOT microhardness indenter using a load of $25 \mathrm{gf}(\cong 0.245 \mathrm{~N})$ for $10 \mathrm{~s}$. Hardness-depth profile measurements in the ferrite substrates were performed for all specimens of the nitrocarburising experiments. Hardness indents were set in the ferrite substrate at selected distances from the interface cementite/ferrite until the middle of the specimen was reached. The exact distance values of the hardness indents from the interface cementite/ferrite were determined by optical microscopy using the software "analySIS" (Soft Imaging System $\mathrm{GmbH})$. For each specific distance value from the interface cementite/ferrite five hardness measurements were made; the average value was taken as the local hardness and the standard deviation was taken as indication of the experimental error. For all specimens of the nitriding experiments, which should have - due to the small specimen thickness and due to the long 
treatment time - a homogeneous nitrogen content, 10 hardness measurements were made across the cross-sectional specimen; their average value and their standard deviation was calculated.

In order to relate the hardness of the ferrite substrate with its nitrogen content, values for both quantities were determined for a couple of specimens with homogeneous nitrogen contents in the ferrite (see section 3). The nitrogen contents of all the nitrided specimens (compound-layer free) were determined by carrier-gas hot extraction. The same procedure was applied to specimens, which were nitrocarburised at $823 \mathrm{~K}$ with a treatment time of $6 \mathrm{~h}$, $14 \mathrm{~h}, 24 \mathrm{~h}$ and $48 \mathrm{~h}$, since these specimens do not exhibit a nitrogen concentration (hardness) gradient across the ferrite substrate in the cross section (cf. Fig. 2b). Prior to nitrogen-content determination by carrier-gas hot extraction on the nitrocarburised specimens, the massive cementite layer was removed by grinding so that only the nitrogen-enriched substrate was analysed. After completion of the grinding procedure, it was checked by X-ray diffraction whether the entire cementite layer had been removed.

To additionally verify the presence or absence of a (cementite) compound layer and of the possible presence of other nitride and carbonitride phases, phase identification was carried out by X-ray diffractometry. A PANalytical X'Pert Multi-Purpose Diffractometer, which was equipped with a graphite monochromator in the diffracted beam, was used. The diffractometer was operated with $\mathrm{CoK} \alpha$ radiation in Bragg-Brentano geometry. Each specimen was rotated around its surface normal during the measurements to achieve better crystallite statistics.

\section{Experimental results and evaluation: hardness measurements and nitrogen-}

\section{content determination}

Each nitrocarburising experiment performed at $783 \mathrm{~K}, 823 \mathrm{~K}$ and $843 \mathrm{~K}$ led to the formation of a massive cementite layer on the ferrite substrates (cf. Fig. 1) $[8,10]$. The cementite layers exhibit a characteristic microstructure (partially rough ferrite-cementite interface) and a 
specific orientation relationship with the ferrite substrate [12]. After cross-sectional metallographic preparation, hardness-depth profile measurements were performed in the ferrite substrate (cf. Figs. 2a - 2c).

In order to transform hardness-depth profiles into nitrogen concentration-depth profiles (cf. Figs. $2 \mathrm{a}-2 \mathrm{c}$ ), the dependence of hardness on nitrogen content in ferrite has to be known. Such a dependence was obtained on the basis of the results for hardness and nitrogen content in homogeneously nitrided/nitrocarburised ferrite given in Table 1 and shown in Fig. 3.

Table 1: The experimentally determined (average) hardness values and (average) nitrogen contents (results from carrier-gas extraction) of all nitrided specimens. Composition $\left(\mathrm{NH}_{3}\right.$ and $\mathrm{H}_{2}$ contents and corresponding nitriding potential) of the nitriding gas atmosphere, yielding compound-layer free specimens, have been indicated. The experiments were performed for 42 $\mathrm{h}$ at $823 \mathrm{~K}$ leading to a homogeneous solid solution of interstitial nitrogen in the ferrite substrate. The hardness of pure iron without any nitrogen dissolved determined in this work equals $100 \pm 2 \mathrm{HV}$. Similar results obtained for some selected (see text) nitrocarburising experiments at $823 \mathrm{~K}$ have been given as well.

\begin{tabular}{|c|c|c|c|c|c|c|c|}
\hline \multicolumn{8}{|c|}{ nitriding experiments } \\
\hline $\mathrm{NH}_{3}$ content [vol.-\%] & 2 & 4 & 6 & 7 & 9 & 12 & 13 \\
\hline $\mathrm{H}_{2}$ content [vol.- $\%$ ] & 98 & 96 & 94 & 93 & 91 & 88 & 87 \\
\hline nitriding potential, $r_{\mathrm{N}}\left[\mathrm{atm}^{-1 / 2}\right]$ & 0.02 & 0.04 & 0.06 & 0.08 & 0.1 & 0.14 & 0.16 \\
\hline hardness [HV] & $116 \pm 7$ & $119 \pm 4$ & $133 \pm 6$ & $147 \pm 3$ & $152 \pm 3$ & $182 \pm 9$ & $205 \pm 7$ \\
\hline nitrogen concentration [at.-\%] & 0.034 & 0.075 & 0.108 & 0.144 & 0.184 & 0.297 & 0.367 \\
\hline
\end{tabular}


nitrocarburising experiments

\begin{tabular}{ccccc}
\hline treatment time [h] & 6 & 14 & 24 & 48 \\
hardness [HV] & $147 \pm 4$ & $158 \pm 2$ & $171 \pm 2$ & $194 \pm 3$ \\
nitrogen concentration [at.-\%] & 0.136 & 0.176 & 0.228 & 0.307 \\
\hline
\end{tabular}

It follows that a linear dependence exists between nitrogen content and hardness of the ferrite substrate:

$$
C_{\mathrm{N}}^{\alpha-\mathrm{Fe}}=m h+b
$$

where $C_{\mathrm{N}}^{\alpha-\mathrm{Fe}}$ denotes the nitrogen concentration in the ferrite substrate, and $h$ its hardness. Least-squares fitting of a straight line to the experimental data in Fig. 3 yielded the following values for $m$ (slope of the straight line in Fig. 3) and $b$ (part cut from the ordinate): $m=(3.46 \pm 0.1) \cdot 10^{-3} \frac{\text { at. } \%}{\mathrm{HV}}$ and $b=-0.354 \pm 0.02$ at. $-\%$. On this basis, the experimentally determined hardness-depth profiles can be transformed into nitrogen concentration-depth profiles (cf. Figs. $2 \mathrm{a}-2 \mathrm{c}$ ). This was done for all considered treatment temperatures $(783 \mathrm{~K}$, $823 \mathrm{~K}$ and $843 \mathrm{~K}$ ) and treatment times.

Such quantitative information on the nitrogen concentration in ferrite cannot be obtained by other techniques. Whereas e.g. carrier-gas hot extraction can only provide an average nitrogen concentration across the whole specimen (instead of a location-resolved nitrogen concentration), the sensitivity of electron probe microanalysis (EPMA) is too low for the presently determined nitrogen concentrations. 


\section{Modelling nitrogen concentration-depth profile development}

\subsection{General assumptions}

The experimentally determined nitrogen concentration-depth profiles will be simulated to analyse, on the basis of comparison with the experimentally determined nitrogen concentration-depth profiles, the diffusivity of nitrogen through cementite.

Consider a laterally infinitely extended iron plate of finite thickness. Nitrogen can enter this plate from both sides; a symmetrical (with respect to the centre plane of the plate) nitrogen concentration-depth profile is built up.

The process of gaseous nitrocarburising can be subdivided into four different steps: (i) diffusion of ammonia from the gas phase to the surface of the specimen, (ii) dissociation of ammonia at the surface, (iii) nitrogen diffusion through the growing cementite layer of timedependent thickness, (iv) nitrogen diffusion within ferrite (after having diffused through the cementite layer) from the interface cementite/ferrite to the core of the specimen. Ad (i): In the present experiments the gas-flow through the quartz-tube furnace is large; the gas composition at the sample surface can be taken constant for a constant treatment temperature [10]. Ad (ii): Already after very short treatment time dissociation of ammonia at the surface of the specimen is not rate determining for the nitrogen uptake; instead nitrogen diffusion through the growing cementite layer is rate-determining (in contrast with the case of nitriding pure ferrite [23]). The conditions indicated under ad (i) and ad (ii) imply that local equilibrium prevails at the interface of the gas atmosphere and the specimen. Furthermore, local equilibrium is assumed to hold at the interface cementite/ferrite, which in the present context in particular implies that there is no chemical-potential gradient for nitrogen at that interface.

Nitrogen diffusion within ferrite is governed by Fick's second law 


$$
\frac{\partial C_{\mathrm{N}}^{\alpha-\mathrm{Fe}}}{\partial t}=D_{\mathrm{N}}^{\alpha-\mathrm{Fe}} \frac{\partial^{2} C_{\mathrm{N}}^{\alpha-\mathrm{Fe}}}{\partial x^{2}}
$$

where $D_{\mathrm{N}}^{\alpha-\mathrm{Fe}}$ is the diffusion coefficient of nitrogen in ferrite (taken as concentration independent), $C_{\mathrm{N}}^{\alpha-\mathrm{Fe}}$ the nitrogen concentration at depth $x$ (measured from the interface cementite/ferrite ${ }^{2}$ ) and $t$ the time of diffusion.

The flux of nitrogen through cementite at the interface cementite/ferrite, $\left.J_{\mathrm{N}}^{\mathrm{Fe}_{3} \mathrm{C}}\right|_{x=0}$, differs from the flux of nitrogen into ferrite at this interface $\left.J_{\mathrm{N}}^{\alpha-\mathrm{Fe}}\right|_{x=0}$ by a term considering the amount of $\mathrm{N}$ consumed by the moving interface cementite/ferrite due to the concentration difference at the interface:

$$
\begin{aligned}
& \left.J_{\mathrm{N}}^{\mathrm{Fe}_{3} \mathrm{C}}\right|_{x=0}=\left.J_{\mathrm{N}}^{\alpha-\mathrm{Fe}}\right|_{x=0}+\left(C_{\mathrm{N}, \text { interface }}^{\mathrm{Fe}_{3} \mathrm{C}}-C_{\mathrm{N}, \text { interface }}^{\alpha}\right) \frac{d S_{\mathrm{Fe}_{3} \mathrm{C}}}{d t} \\
& =-\left.D_{\mathrm{N}}^{\alpha-\mathrm{Fe}} \frac{\partial C_{\mathrm{N}}^{\alpha-\mathrm{Fe}}}{\partial x}\right|_{x=0}+\left(C_{\mathrm{N}, \text { interface }}^{\mathrm{Fe}_{3} \mathrm{C}}-C_{\mathrm{N}, \text { interface }}^{\alpha}\right) \frac{d S_{\mathrm{Fe}_{3} \mathrm{C}}}{d t}
\end{aligned}
$$

\footnotetext{
${ }^{2}$ The cementite layer is thin compared to the ferrite substrate at all considered treatment times and the cementite layer grows much slower than the extent of the nitrogen concentration-depth profile in the substrate. Therefore, the consumption of a part of the ferrite upon formation of the cementite is neglected in the modelling of the diffusion of nitrogen in ferrite.
} 
where $x=0$ denotes the location coordinate which represents the interface cementite/ferrite. There are no reliable data about the $\mathrm{N}$ content in cementite (it is even unclear whether the concentration difference in Eq. (3) should be positive or negative). However, test calculations with nitrogen contents in cementite ranging from 0 at. $\%$ to 0.5 at. $\%$ indicate that - given the known growth rate of cementite - the nitrogen consumption or release due to the growing cementite (at the cost of ferrite with a nitrogen content of $C_{\mathrm{N}, \text { interface }}^{\alpha-\mathrm{Fe}}$ ) is negligible compared to the overall nitrogen flux through the cementite layer.

Nitrogen enters the ferrite substrate at both sides. Hence, a symmetrical nitrogen concentration-depth profile results and no net flux of nitrogen through the middle of the sample occurs, leading to the second boundary condition

$$
\left.\frac{\partial C_{\mathrm{N}}^{\alpha-\mathrm{Fe}}}{\partial x}\right|_{x=Z}=0
$$

where $x=Z$ denotes the position of the centre plane.

Before nitrogen can pass the interface cementite/ferrite and can diffuse through ferrite, it must be transported through the cementite layer. Nitrogen diffusion through cementite is provoked by a gradient of the chemical potential of nitrogen across the cementite layer (cf. Fig. 4)

$$
F=-\left(\frac{\partial \mu_{\mathrm{N}}^{\mathrm{Fe}_{3} \mathrm{C}}}{\partial x}\right)_{p, T},
$$

where $F$ is the thermodynamic force, $\mu_{\mathrm{N}}^{\mathrm{Fe}_{3} \mathrm{C}}$ the chemical potential of nitrogen in cementite and $x$ the location coordinate, $T$ the treatment temperature and $p$ the pressure. 
For the nitrogen flux through cementite, $J_{\mathrm{N}}^{\mathrm{Fe}_{3} \mathrm{C}}$, it holds that [24]

$$
\begin{aligned}
J_{\mathrm{N}}^{\mathrm{Fe}_{3} \mathrm{C}} & =v_{\mathrm{N}}^{\mathrm{Fe}_{3} \mathrm{C}} C_{\mathrm{N}}^{\mathrm{Fe}_{3} \mathrm{C}}=M_{\mathrm{N}}^{\mathrm{Fe}_{3} \mathrm{C}} F C_{\mathrm{N}}^{\mathrm{Fe}_{3} \mathrm{C}} \\
& =-M_{\mathrm{N}}^{\mathrm{Fe}_{3} \mathrm{C}} C_{\mathrm{N}}^{\mathrm{Fe}_{3} \mathrm{C}}\left(\frac{\partial \mu_{\mathrm{N}}^{\mathrm{Fe}_{3} \mathrm{C}}}{\partial x}\right)_{p, T}=-D_{\mathrm{N}}^{\mathrm{Fe}_{3} \mathrm{C}}\left(\frac{\partial C_{\mathrm{N}}^{\mathrm{Fe}_{3} \mathrm{C}}}{\partial x}\right)_{p, T},
\end{aligned}
$$

where $v_{\mathrm{N}}^{\mathrm{Fe}_{3} \mathrm{C}}$ denotes the drift velocity of nitrogen in cementite, $M_{\mathrm{N}}^{\mathrm{Fe}_{3} \mathrm{C}}$ is the mobility of nitrogen in cementite, $D_{\mathrm{N}}^{\mathrm{Fe}_{3} \mathrm{C}}$ represents the diffusion coefficient of nitrogen in cementite and $C_{\mathrm{N}}^{\mathrm{F}_{3} \mathrm{C}}$ is the nitrogen concentration in cementite. The diffusion coefficient of nitrogen in cementite can be expressed by

$$
D_{\mathrm{N}}^{\mathrm{Fe}_{3} \mathrm{C}}=M_{\mathrm{N}}^{\mathrm{Fe}_{3} \mathrm{C}} R T\left(1+\frac{\partial \ln \gamma_{\mathrm{N}}^{\mathrm{Fe}_{3} \mathrm{C}}}{\partial \ln C_{\mathrm{N}}^{\mathrm{Fe}_{3} \mathrm{C}}}\right),
$$

where $\left(1+\frac{\partial \ln \gamma_{N}^{\mathrm{Fe}_{3} \mathrm{C}}}{\partial \ln C_{\mathrm{N}}^{\mathrm{Fe}_{3} \mathrm{C}}}\right)$ is the thermodynamic factor, with $\gamma_{\mathrm{N}}^{\mathrm{Fe}_{3} \mathrm{C}}$ as the activity coefficient of nitrogen in cementite. The solubility of nitrogen in cementite is extremely small, e.g. for 1593 $\mathrm{K}$ a solubility of about 0.064 at.-\% was reported [25]. Due to this extremely limited solubility, Henry's law $[26,27]$ is assumed for nitrogen in cementite. Consequently, the thermodynamic factor equals one and $D_{\mathrm{N}}^{\mathrm{Fe}_{3} \mathrm{C}}$ reduces to

$$
D_{\mathrm{N}}^{\mathrm{Fe}_{3} \mathrm{C}}=M_{\mathrm{N}}^{\mathrm{Fe}_{3} \mathrm{C}} R T=D_{\mathrm{N}}^{*} \mathrm{Fe}_{3} \mathrm{C}
$$

where $D_{\mathrm{N}}^{*, \mathrm{Fe}_{3} \mathrm{C}}$ is the (tracer-)diffusion coefficient of nitrogen in cementite. Thus, 


$$
J_{\mathrm{N}}^{\mathrm{Fe}_{3} \mathrm{C}}=-D_{\mathrm{N}}^{*}, \mathrm{Fe}_{3} \mathrm{C}\left(\frac{\partial C_{\mathrm{N}}^{\mathrm{Fe}_{3} \mathrm{C}}}{\partial x}\right)_{p, T} .
$$

A linear concentration profile of nitrogen across cementite is assumed in Eq. (6b). The concentration difference of nitrogen across the cementite layer is given by the difference of the nitrogen concentration in cementite at the interface gas atmosphere/cementite, $C_{\mathrm{N}, \text { surface }}^{\mathrm{Fe}_{3} \mathrm{C}}$, and the nitrogen concentration in cementite at the interface cementite/ferrite, $C_{\mathrm{N}, \text { interface }}^{\mathrm{Fe}_{3} \mathrm{C}}$. Then Eq. (6b) can be given as

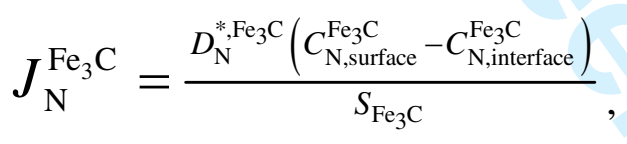

where $S_{\mathrm{Fe}_{3} \mathrm{C}}$ is the cementite-layer thickness.

The nitrogen concentrations in cementite at both interfaces (gas atmosphere/cementite and at the interface cementite/ferrite) will be expressed in terms of "corresponding" (see what follows) nitrogen concentrations in ferrite. For both, cementite and ferrite, Henry's law can be adopted. Therefore, for cementite and ferrite in (hypothetical) equilibrium with each other and, possibly additionally, with the same outer gas atmosphere, the concentrations of nitrogen in cementite, $C_{\mathrm{N}}^{\mathrm{Fe}_{3} \mathrm{C}}$, and in ferrite, $C_{\mathrm{N}}^{\alpha-\mathrm{Fe}}$, are in equilibrium related $\mathrm{by}^{3}$

\footnotetext{
${ }^{3}$ For the chemical potential of nitrogen in cementite it holds that $\mu_{\mathrm{N}}^{\mathrm{Fe}_{3} \mathrm{C}}=\mu_{\mathrm{N}}^{0}+R T \ln \gamma_{\mathrm{N}}^{\mathrm{Fe}_{3} \mathrm{C}} x_{\mathrm{N}}^{\mathrm{Fe}_{3} \mathrm{C}}$ and for the chemical potential of nitrogen in ferrite it holds that $\mu_{\mathrm{N}}^{\alpha-\mathrm{Fe}}=\mu_{\mathrm{N}}^{0}+R T \ln \gamma_{\mathrm{N}}^{\alpha-\mathrm{Fe}} x_{\mathrm{N}}^{\alpha-\mathrm{Fe}}$. Assuming for both, cementite and ferrite, the same reference state and Henry's law (constant activity coefficient of nitrogen), the mole fractions of nitrogen in cementite and ferrite in equilibrium with each other are related by a partition
} 
$C_{\mathrm{N}}^{\mathrm{Fe}_{3} \mathrm{C}}=\varphi C_{\mathrm{N}}^{\alpha-\mathrm{Fe}}$

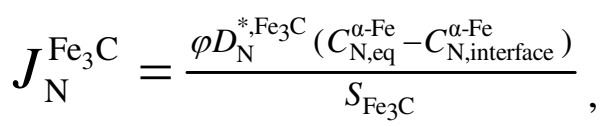

where $\varphi$ is the partition coefficient. Hence, the nitrogen concentration in ferrite at the cementite/ferrite interface in (real, local) equilibrium with cementite at the same interface corresponds to $C_{\mathrm{N}, \text { interface }}^{\alpha-\mathrm{Fe}}=C_{\mathrm{N}, \text { interface }}^{\mathrm{Fe}_{3} \mathrm{C}} / \varphi$ and thus $C_{\mathrm{N}, \text { interface }}^{\mathrm{Fe}_{3} \mathrm{C}}=\varphi C_{\mathrm{N}, \text { interface }}^{\alpha-\mathrm{ee}}$. Diffusion of nitrogen through the cementite will come to a halt if the nitrogen concentration in the ferrite corresponds to the nitrogen concentration which would prevail in ferrite in (hypothetical) equilibrium with the gas atmosphere, $C_{\mathrm{N}, \mathrm{eq}}^{\alpha-\mathrm{Fe}}$. Hence, the concentration of nitrogen in cementite at the surface in (real, local) equilibrium with the gas atmosphere, $C_{\mathrm{N}, \text { surface }}^{\mathrm{Fe}_{3} \mathrm{C}}$, is given by $C_{\mathrm{N}, \text { surface }}^{\mathrm{Fe}_{3} \mathrm{C}}=\varphi C_{\mathrm{N}, \mathrm{eq}}^{\alpha-\mathrm{Fe}}$.

The above consideration implies that Eq. (9) can be written as

The cementite-layer thickness $S_{\mathrm{Fe}_{3} \mathrm{C}}$ has been determined experimentally for the present samples. The layer thickness could be described for each temperature by adopting a modified parabolic growth law $[8,10]$

$$
S_{\mathrm{Fe}_{3} \mathrm{C}}^{2}(t)=k(T) t+S_{0}^{2}(T)
$$

coefficient, $\varphi$, according to $\varphi=\frac{\gamma_{\mathrm{N}}^{\mathrm{d} \text {.Fe }}}{\gamma_{\mathrm{N}}^{\mathrm{Fe}_{3} \mathrm{C}}}$. It will be assumed that for the minute range of nitrogen concentration in cementite $\varphi$ does not depend on nitrogen concentration. 
where $k$ denotes the parabolic growth constant for cementite and $S_{0}$ a (hypothetical) initial cementite-layer thickness at $t=0$ (see discussion in Ref. [8]). Combining Eqs. (11) and (12)

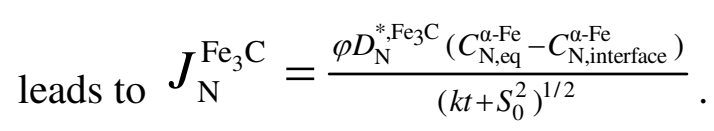

\subsection{Simulation of nitrogen concentration-depth profiles; numerical procedure}

For the simulation of the nitrogen concentration-depth profiles, Fick's first and second law have to be solved subject to the boundary conditions given by Eqs. (3) and (4). This can be done numerically on the basis of the method after Crank and Nicolson [23, 28] using the implicit finite-difference method. For that purpose the nitrogen concentration profile within ferrite was calculated for equidistant grid points in space (distance $\Delta x$ ) (cf. Fig. 4) at different time steps (see what follows in section 5). Details of the numerical procedure are described in supplementary material published together with the online version.

\section{Results of the simulation}

The simulation was performed with $M=100$ grid points (up to the middle of the specimen) and different time steps. The increment of time was increased by $0.5 \%$ after each generation of a nitrogen concentration profile [23], recognising the decrease of the nitrogenconcentration gradients with time, in order to reduce calculation time. Doing this, the condition $r=\frac{D_{\mathrm{N}}^{*}, \mathrm{Fe}_{3} \mathrm{C}}{(\Delta x)^{2}} \leq 1 / 2$ has to be fulfilled [28], where $\Delta t$ denotes the increment of the time and $\Delta x$ denotes the grid-point distance. The simulation was started at the respective treatment temperatures on the basis of the nitrogen concentration-depth profile determined after $6 \mathrm{~h}$, since for smaller treatment times the diffusion geometry and mechanism is incompatible with the model (see section 6.2). 
Table 2: Results of the simulation of nitrogen concentration-depth profiles. The equilibrium nitrogen concentration in ferrite, and the product of the partition coefficient and the (tracer)diffusion coefficient of nitrogen through cementite were refined by matching of the simulated data and the experimental data by least-squares fitting. Furthermore, the diffusion coefficient of nitrogen in ferrite has been given according to Ref. [29].

treatment temperature, $T$

$[\mathrm{K}]$

equilibrium nitrogen concentration in ferrite, $C_{\mathrm{N}, \mathrm{eq}}^{\alpha-\mathrm{Fe}}$

product of the partition coefficient and the (tracer-)diffusion coefficient of nitrogen through

$$
2.9 \cdot 10^{-15} \quad 4.8 \cdot 10^{-15} \quad 5.9 \cdot 10^{-15}
$$

cementite, $\varphi D_{\mathrm{N}}^{*, \mathrm{Fe}_{3} \mathrm{C}}\left[\mathrm{m}^{2} / \mathrm{s}\right]$ 
diffusion coefficient of nitrogen in ferrite, $D_{\mathrm{N}}^{\alpha-\mathrm{Fe}}$

$$
7.4 \cdot 10^{-12} 1.3 \cdot 10^{-11} 1.8 \cdot 10^{-11}
$$

$\left[\mathrm{m}^{2} / \mathrm{s}\right]$

\begin{abstract}
Adopting an Arrhenius-type temperature dependence for the (tracer-)diffusion coefficient of nitrogen in cementite and taken the partition coefficient $\varphi$ as temperature independent, a plot of the logarithm of $\varphi D_{\mathrm{N}}^{*, \mathrm{Fe}_{3} \mathrm{C}}$ vs. $1 / T$ should yield a straight line. This is observed indeed; see Fig. 5. The slope of the straight line obtained equals $-Q / R$, with $Q$ as the activation energy of nitrogen diffusion in cementite and $R$ as the gas constant. It follows: $Q=65 \pm 2 \mathrm{~kJ} / \mathrm{mol}$
\end{abstract}

\title{
6. Concluding discussion
}

\subsection{Hardness/concentration-depth profiles}

The hardness of the ferrite substrates increases linearly with the nitrogen concentration. Upon embedding (cf. section 2), which has to be considered as a heat treatment, the nitrogen in the ferrite forms (semi-)coherent $\alpha$ ' $-\mathrm{Fe}_{16} \mathrm{~N}_{2}$ precipitates [30-34], which are responsible for the hardness increase as measured at room temperature. In order to guarantee comparability of the hardness measurements, the embedding has to be performed in a reproducible way. Therefore, a special standard embedding procedure was developed, which has been described in section 2.

In the course of relating the ferrite hardness with the nitrogen content in the ferrite, the effect of present carbon was neglected. The amount of carbon which can be dissolved in ferrite at $823 \mathrm{~K}$ is more than twenty times smaller than the amount of nitrogen (see introduction). Already because of this recognition it is expected that a much smaller 
hardening effect due to carbides in ferrite is expected than due to nitrides. Indeed, for carbon in ferrite an increase of Vickers hardness of at maximum of $15 \mathrm{HV}$ was observed in Ref. [35], which is much less than the maximum increase of $100 \mathrm{HV}$ observed for nitrogen in ferrite (cf. Figure 3). Moreover, in Ref. [35] the solid solution treatment prior to the age hardening was performed at temperatures as high $973 \mathrm{~K}$, which certainly led to dissolution of more carbon in the ferrite than in the present experiments conducted at $\leq 843 \mathrm{~K}$. Thus the (maximum possible) hardening effect due to carbon in ferrite in the present work is expected to be even smaller than $15 \mathrm{HV}$. Further, the data points in Figure 3 do not differ systematically from the common straight line, independently of whether the points originate from a nitrocarburised specimen (containing some carbon in the ferrite) or from purely nitrided specimen (containing no carbon in the ferrite), confirming that the hardness depends practically only on the nitrogen content in the ferrite.

Moreover, it must be noted that the calibration line shown in Fig. 3 was determined on the basis of experiments performed at $823 \mathrm{~K}$. This calibration line was also applied to the data obtained at $783 \mathrm{~K}$ and 843 . The true relation between hardness and nitrogen content at $783 \mathrm{~K}$ and $843 \mathrm{~K}$ may differ slightly from that pertaining at $823 \mathrm{~K}$. This may be the origin of the slightly negative nitrogen-concentration values in the ferrite substrate for some data points at very short treatment times $(0.5 \mathrm{~h}$ and $2 \mathrm{~h})$ at $783 \mathrm{~K}$ (cf. Fig. 2a).

The data obtained for the nitrogen concentration-depth profiles at the three different considered treatment temperatures indicate pronounced nitrogen concentration gradients in the ferrite matrix at short treatment times as $0.5 \mathrm{~h}$ and $2 \mathrm{~h}$; the concentration gradients level off with increasing treatment time. The development of the nitrogen concentration-depth profile in the ferrite substrate is dominated by two processes: (i) nitrogen transport through the cementite layer via diffusion. The cementite-layer thickness increases as a function of the treatment time (according to a modified parabolic growth law $[8,10])$. Therefore, the nitrogen flux trough cementite decreases with increasing treatment time. (ii) The inward-diffusion of 
nitrogen into the ferrite substrate remains relatively fast. From (i) and (ii) it is concluded that the initially large nitrogen concentration gradient in the ferrite substrate decreases with time, as observed.

\subsection{Simulation of nitrogen concentration-depth profiles}

In the present work, nitrogen concentration-depth profiles in the ferrite substrate with a growing cementite layer at the surface were simulated. In the literature [23] such an approach was already applied for the calculation of nitrogen concentration-depth profiles of compoundlayer free ferrite specimens. In that case local equilibrium between gas atmosphere and the surface of the specimen was not immediately established. Therefore, nitrogen absorption and/or ammonia dissociation and nitrogen transfer through the surface contributed significantly to the process kinetics. In fact, nitrogen transfer through the cementite layer in the present case and nitrogen transfer through the surface in case of nitriding ferrite without compound layer at the surface (Ref. [23]) can be conceived as analogues. However, different dependences on $\left(C_{\mathrm{N}, \text { eq }}^{\alpha-\mathrm{Fe}}-C_{\mathrm{N}, \text { interface }}^{\alpha-\mathrm{Fe}}\right)$ occur in both cases: In Ref. [23]:

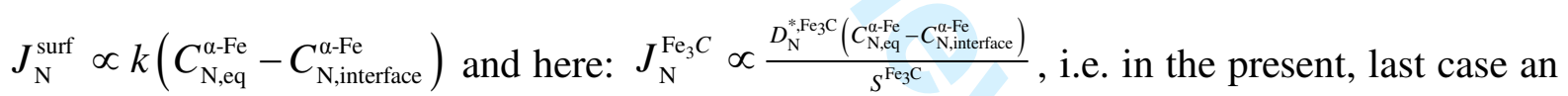
extra time dependence, through $S^{\mathrm{Fe}_{3} \mathrm{C}}$, is introduced.

Treatment times of $0.5 \mathrm{~h}$ and $2 \mathrm{~h}$ were not considered in the simulation procedure. In the early stage of cementite formation $(t<6 \mathrm{~h})$, cementite-layer growth proceeded faster than as predicted by the developed model. This can be explained as follows: (i) in the early stage of cementite formation an incompletely closed cementite layer is present $[8,10]$. Nitrogen diffusion from the surface of the specimen into ferrite proceeds directly, i.e. bypassing cementite $^{4}$. (ii) Further, just after the formation of a closed cementite layer, short-circuit diffusion of nitrogen through thin and defect-rich parts of the cementite layer occurs. In this stage of cementite formation, cementite is expected to exhibit a relatively high grain-boundary

\footnotetext{
${ }^{4}$ Transport of nitrogen in ferrite is much faster than transport of nitrogen through cementite.
} 
density; for data demonstrating grain-boundary diffusion in cementite, see Ref. [12]. Due to such a 'bypass/short-circuit' mechanism, nitrogen can be transported relatively fast through the cementite layer in the early stage of cementite formation ${ }^{5}$. Therefore, treatment times $<6$ $\mathrm{h}$ were not used in the data evaluation on the basis of the model developed in section 4.1.

Literature data for the equilibrium nitrogen concentration in ferrite vary considerably: e.g. the values reported in Ref. [36] are distinctly lower than the values reported in Ref. [17]. The values of $C_{\mathrm{N}, \mathrm{eq}}^{\alpha-\mathrm{Fe}}$ obtained in the present work are generally larger than those compatible with the data from Refs. [17] and [36]. These differences can be understood recognising that the nitrogen concentration in the ferrite substrate, $C_{\mathrm{N}, \text { eq }}^{\alpha-\mathrm{Fe}}$, as determined in the present work, pertains to the (hypothetical) equilibrium of ferrite with the present nitrocarburising gas atmosphere. In reality such an equilibrium cannot occur: for such high nitrogen concentrations, solubility limits for nitrogen in ferrite in equilibrium with iron (carbo-)nitrides are surpassed, and formation of $\gamma^{\prime}-\mathrm{Fe}_{4} \mathrm{~N}$ below $833 \mathrm{~K}$ or of $\varepsilon-\mathrm{Fe}_{3}(\mathrm{~N}, \mathrm{C})_{1+x}$ above $843 \mathrm{~K}$ [11] occurs. Indeed, in the present work, treatment times $\gg 48 \mathrm{~h}$ at $853 \mathrm{~K}$ occasionally led to the formation of these (carbo-)nitride phases at the cementite/ferrite interface.

According to the knowledge of the present authors, diffusion data of nitrogen in cementite have not been reported, before. The values obtained for the product of the partition coefficient and the (tracer-)diffusion coefficient of nitrogen through cementite are considerably lower than values for the diffusion coefficients of nitrogen in ferrite [29, 37] (cf. Table 2) and iron nitrides [38-41] at similar treatment temperatures. The role of the cementite layer as diffusion barrier for nitrogen can be illustrated by assuming that the cementite layer would instead consist of ferrite. In that case, in Eq. (11) $\varphi D_{\mathrm{N}}^{*, \mathrm{Fe}_{3} \mathrm{C}}$ should be substituted by $D_{\mathrm{N}}^{\alpha-\mathrm{Fe}}$. Hence, the nitrogen flux through the (cementite) surface layer, $J_{\mathrm{N}}^{\mathrm{Fe}_{3} \mathrm{C}}$, would increase

\footnotetext{
${ }^{5}$ A similar explanation was used for the observed enhanced initial growth rate during carbon-diffusion controlled cementite-layer growth on ferrite $[8,10]$.
} 
by a factor $D_{\mathrm{N}}^{\alpha-\mathrm{Fe}} / \varphi D_{\mathrm{N}}^{*} \mathrm{Fe}_{3} \mathrm{C}$, i.e. a factor of about 2500 - 3000 (cf. Table 2). This clearly demonstrates the diffusion-barrier behaviour of the cementite layer for nitrogen, which then could be due in particular to the very low solubility of nitrogen in cementite, leading to very small values of $\varphi$; further, the pre-exponential factors contained in $D_{\mathrm{N}}^{\alpha-\mathrm{Fe}}$ and $D_{\mathrm{N}}^{*, \mathrm{Fe}_{3} \mathrm{C}}$ may differ considerably.

The activation energy of nitrogen diffusion through cementite (here determined as $65 \pm$ $2 \mathrm{~kJ} / \mathrm{mol}$ ) is relatively low as compared to real or "apparent" activation energies for carbon diffusion through cementite which are in the range of $110-185 \mathrm{~kJ} / \mathrm{mol}$ [10, 42-44], and for nitrogen diffusion in iron nitrides, which are in the range of $92-144 \mathrm{~kJ} / \mathrm{mol}[40,41,45]$. The activation energy for nitrogen diffusion in cementite appears to be as low as the activation energy for nitrogen (or carbon) diffusion in ferrite, which is about $78-79 \mathrm{~kJ} / \mathrm{mol}[29,37]$. One possibility is that $\varphi$, although very small, depends significantly on temperature and thus affects the activation energy value determined. Another possibility is that the low activation energy for $D_{\mathrm{N}}^{*, \mathrm{Fe}_{3} \mathrm{C}}$ may hint at nitrogen transport favourably occurring via cementite grain boundaries; preferred diffusion of carbon along grain boundaries in cementite was reported very recently [12]. A role of defects (which later-on heal out) has indeed already been discussed above for the initial fast stage of nitrogen transport through cementite (see paragraph 2 of the present section 6.2), but it is imaginable that still later nitrogen diffusion along remaining grain boundaries (or other extended defects) may contribute to the occurring nitrogen flux through cementite. As long as the grain-boundary density remains constant, the grain boundaries' contribution to the nitrogen transport will lead to same kinetic equations as derived in section 4, and the obtained diffusion coefficient becomes an "effective" diffusion coefficient and the activation energy is an "effective" activation energy [46].

\section{Conclusions}


(i) Hardness-depth profile measurements provide a suitable method to quantitatively determine nitrogen-concentration depth profiles in ferrite (maximal nitrogen content: $\approx 0.4$ at.- $\%$ ) after well-defined thermal post-treatment on the basis of a calibration. The relation between hardness and nitrogen content was found to be linear.

(ii) Massive cementite layers with a time-dependent thickness can be generated on ferrite substrates by gaseous nitrocarburising at $783 \mathrm{~K}, 813 \mathrm{~K}$ and $843 \mathrm{~K}$. The nitrogen concentration-depth profile in the ferrite substrate underneath the growing cementite layer can be simulated on the basis of a developed model using the implicit finite-difference method, yielding values for the diffusivity of nitrogen through cementite.

(iii) The effective activation energy of nitrogen diffusion through cementite is about as large as the activation energy of nitrogen diffusion in ferrite. This may hint at nitrogen grain-boundary diffusion as dominant transport mechanism of nitrogen through cementite. The cementite layer acts as a diffusion barrier for nitrogen in particular because of the very low solubility of nitrogen in cementite. 


\section{References}

[1] P. M. Unterweiser and A.G. Gray, editors: Source Book on Nitriding. ASM, Metals Park, OH, (USA), 1977.

[2] D. Liedtke, U. Baudis, J. Boßlet, U. Huchel, H. Klümper-Westkamp, W. Lerche and H.-J. Spieß H-J: Wärmebehandlung von Eisenwerkstoffen - Nitrieren und Nitrocarburieren. Expert-Verlag, Renningen-Malmsheim (Germany), 2006.

[3] T.B. Massalski and H. Okamoto, editors: Binary Alloy Phase Diagrams, ASM International, Metals Park, OH (USA), 1990.

[4] H. Du and M. Hillert: Z. Metallkde., 1991, vol. 82, pp. 310-316.

[5] C.H. Knerr, T.C. Rose, J.H. Filkowski. In: J.R. Davis, G.M. Davidson, S.R. Lampman, T.B. Zorc, J.L. Daquila, A.W. Ronke, et al., editors: ASM Handbook, vol. 4, Heat Treating, ASM International, Metals Park, OH (USA), 1991, pp. 387-409.

[6] P.F. Colijn, E.J. Mittemeijer and H.C.F. Rozendaal: Z. Metallkde., 1983, vol. 74, pp. 620627.

[7] M. A. J. Somers and E. J. Mittemeijer: Surf. Eng., 1987, vol. 3, pp. 123-137.

[8] T. Gressmann, M. Nikolussi, A. Leineweber and E.J. Mittemeijer: Scr. Mat., 2006; vol. 55, pp. 723-726.

[9] E.J. Mittemeijer: J. Heat Treating, 1983, vol. 3, pp. 114-119.

[10] M. Nikolussi, A. Leineweber and E.J. Mittemeijer: J. Mater. Sci., 2009, vol. 44, pp. 770777.

[11] M. Nikolussi, A. Leineweber and E.J. Mittemeijer: Int. J. Mat. Res., 2007, vol. 98, pp. 1086-1092.

[12] M. Nikolussi, A. Leineweber and E.J. Mittemeijer: Acta Mat., 2008, vol. 56, pp. 58375844.

[13] A. Leineweber, T. Liapina, T. Gressmann, M. Nikolussi and E. J. Mittemeijer: Adv. Sci. Techn., 2006, 46, 32-41. 
[14] M. Nikolussi, S. Shang, T. Gressmann, A. Leineweber, E. J. Mittemeijer, Y. Wang and Z.-K. Liu: Scr. Mat., 2008, vol. 59, 814-817.

[15] Sone, T., Tsunasawa, E. Yamanaka, K.: Trans. Japan Inst. Met., 1981 vol. 22, pp. 237243.

[16] A. Schneider and H. J. Grabke: Mater. Corr., 2003, vol. 54, pp. 793-804.

[17] J. Kunze: Nitrogen and Carbon in Iron and Steel. Akademie-Verlag, Berlin (Germany), 1990.

[18] E.J. Mittemeijer and J.T. Slycke: Surf. Eng., 1996, vol. 12, pp. 152-162.

[19] E. Lehrer: Z. Elektrochem., 1930, vol. 36, pp. 383-392.

[20] R. Chatterjee-Fischer, R. Bodenhagen, F.-W. Eysell, R. Hoffmann, D. Liedtke, H. Mallener, W. Rembges, A. Schreiner and G. Welker: Wärmebehandlung von Eisenwerkstoffen. Expert-Verlag, Renningen-Malmsheim, 1995.

[21] A. Wells: J. Mat. Sci., 1985, vol. 20, pp. 2439-2445.

[22] G. Petzow: Metallographic Etching. ASM International, Materials Park, OH (USA), 1999.

[23] H.C.F. Rozendaal, E.J. Mittemeijer, P.F. Colijn and P.J. van der Schaaf: Metall. Trans. A, 1983, vol. 14A, pp. 395-399.

[24] P.G. Shewmon: Diffusion in Solids. 2nd ed., The Minerals, Metals \& Materials Society 1989.

[25] A. Kagawa and T. Okamoto: Trans. Japan Inst. Met., 1981, vol. 22, vol. 137-143.

[26] P.W. Atkins: Physikalische Chemie. Wiley-VCH, Weinheim (Germany), 2001.

[27] G. Wedler: Lehrbuch der physikalischen Chemie.Wiley-VCH, Weinheim (Germany) 2007.

[28] J. Crank: The Mathematics of Diffusion. $2^{\text {nd }}$ edition, Oxford Science Publications (UK), 1975.

[29] M. Weller: Mater. Sci. Forum, 2001, vol. 366-368, pp. 95-137. 
[30] E. Kubalek: Härterei Tech. Mitt., 1968, vol. 23, pp. 177-197.

[31] D.H. Jack and K.H. Jack: Mat. Sci. Eng., 1973, vol. 11, pp. 1-27.

[32] Y. Inokuti, N. Nishida and N. Ōhashi: Metall. Trans. A, 1975, vol. 6A, pp. 773-784.

[33] U. Dahmen, P. Ferguson and K.H. Westmacott: Acta Metall., 1987, vol. 35, pp. 10371046.

[34] Z.Q. Liu, Y.X. Chen, Z.K. Hei, D.X. Li and H. Hashimoto: Metall. Mater. Trans. A, 2001, vol. 32A, pp. 2681-2688.

[35] Tsou, A. L., Nutting, J., Menter, J.W.: J. Iron Steel Inst., 1952, pp. 163-171.

[36] B.J. Kooi, M.A.J. Somers and E.J. Mittemeijer: Metall. Mater. Trans. A, 1996, vol. 27A, pp. $1055-1061$.

[37] J.D. Fast and M.B. Verrijb: J. Iron Steel Inst., 1954, vol. 176, pp. 24-27.

[38] K. Schwerdtfeger, P. Grieveson and E.T. Turkdogan: Trans. Metall. Soc. AIME, 1969, vol. 245, pp. 2461-2466.

[39] M.A.J. Somers and E.J. Mittemeijer: Metall. Mater. Trans. A, 1995, vol. 26A, pp. 57-74.

[40] E.J. Mittemeijer and M.A.J. Somers: Surf. Eng., 1997, vol. 13, pp. 483-497.

[41] T. Liapina, A. Leineweber and E.J. Mittemeijer: Metall. Mater. Trans. A, 2006, vol. 37A, pp. 319-330.

[42] B. Ozturk, V.L. Fearing, J.A. Ruth and G. Simkovich: Metall. Trans. A, 1982, vol. 13A, pp. 1871-1873.

[43] B. Ozturk, V.L. Fearing, J.A. Ruth and G. Simkovich: Solid State Ionics, 1984, vol. 12, pp. $145-151$.

[44] M. Hillert, L. Höglund and J. Ågren: J. Appl. Phys., 2005, vol. 98, 053511 pp. 1-6.

[45] A. Leineweber: Acta Mat., 2007, vol. 55, pp. 6651-6658.

[46] J. Philibert: Atom movements, diffusion and mass transport in solids, Les Éditions de Physique (F), 1991. 
Figure 2: Experimentally determined hardness-depth profiles in the ferrite substrate with a massive cementite layer of time-dependent thickness at the surface of the ferrite substrate (dots; cf. hardness axes). Hardness-depth profiles were transformed into nitrogen concentration-depth profiles (dots; cf. nitrogen-concentration axes) applying the calibrated hardness-nitrogen concentration relation (cf. Fig. 3). The simulated nitrogen concentrationdepth profiles are shown by the continuous curves. The dashed curves connect the data points pertaining to the hardness/nitrogen concentration-depth profiles for $0.5 \mathrm{~h}$ and $2 \mathrm{~h}$, which were not considered for the simulation. Experiments as well as simulations were performed at (a) $783 \mathrm{~K}$, (b) $823 \mathrm{~K}$ and (c) $843 \mathrm{~K}$.

Figure 3: Calibration line: Nitrogen concentration (determined by carrier-gas hot extraction; the error is smaller than the size of the dots) vs. the hardness for homogeneous ferrite substrates (determined by micro-Vickers hardness indentations). The straight line was determined by least-squares fitting of Eq. (1) to the experimental data. Solid data points indicate results from nitrided specimens, open data points indicate results from nitrocarburised specimens.

Figure 4: Schematic drawing of a cementite layer on a ferrite substrate (cross-sectional view). A gradient of the chemical potential of nitrogen in cementite provokes the flux of nitrogen 
through cementite. Consequently, a nitrogen concentration-depth profile develops in the ferrite substrate, which can be calculated for different time steps and grid points using the model described in section IV and the appendix applying the implicit finite-difference method. Local equilibrium at the gas-solid interface and at the cementite/ferrite interface is assumed.

Figure 5: Arrhenius plot: natural logarithm of the product of the partition coefficient and the (tracer-)diffusion coefficient of nitrogen through cementite, $\varphi D_{\mathrm{N}}^{*}{ }_{\mathrm{Fe}} \mathrm{C}$, versus the reciprocal temperature $1 / T$. 


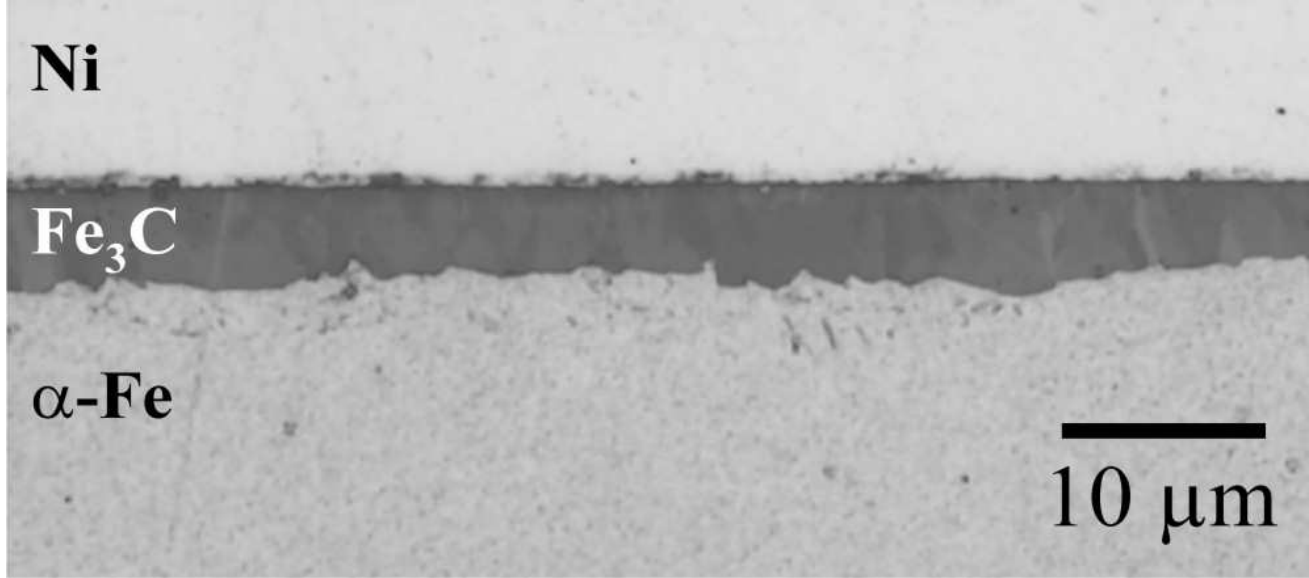

Figure 1

$83 \times 37 \mathrm{~mm}(300 \times 300$ DPI $)$ 


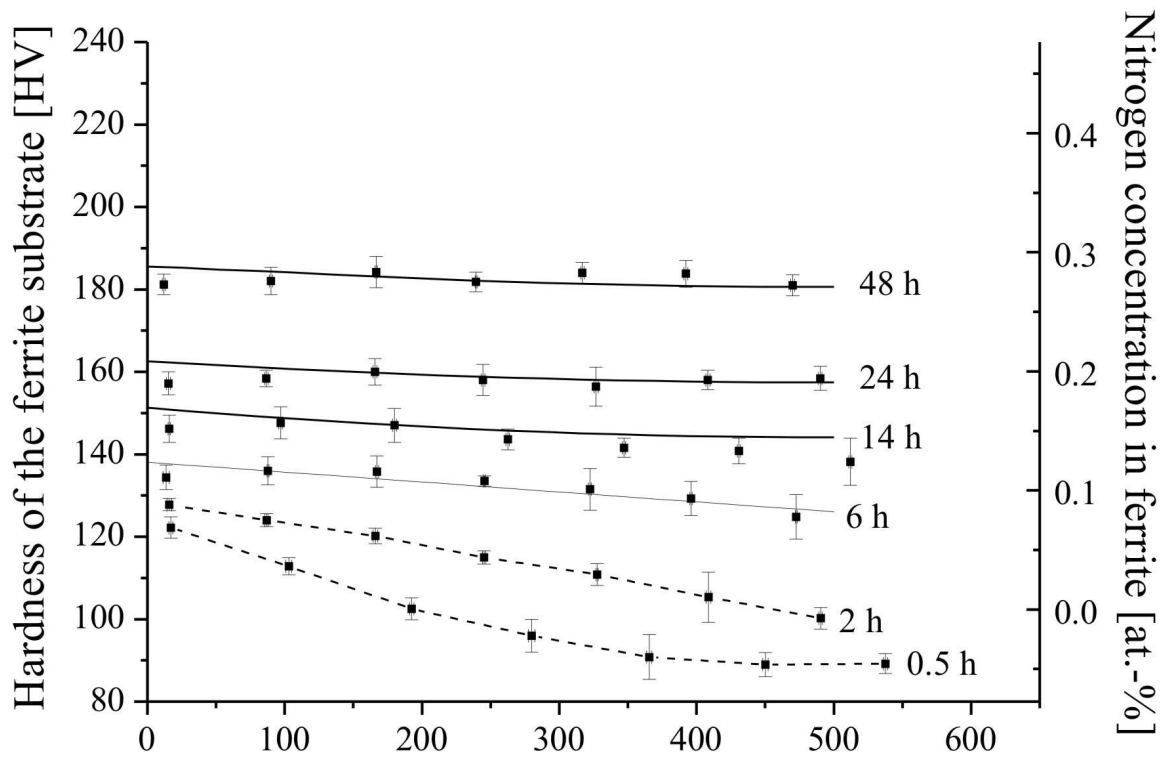

Distance from the interface cementite/ferrite $[\mu \mathrm{m}]$

Figure $2 a$

$83 \times 61 \mathrm{~mm}(600 \times 600 \mathrm{DPI})$ 
Figure $3 b$

$83 \times 62 \mathrm{~mm}(600 \times 600$ DPI $)$ 


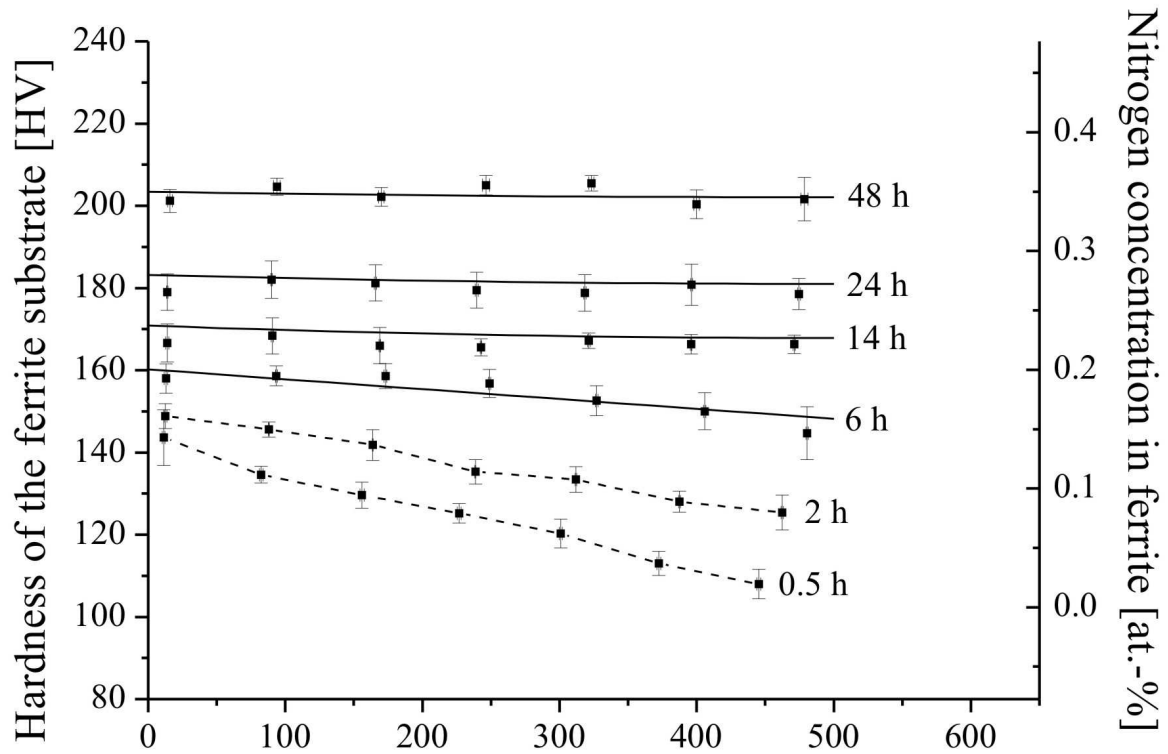

Distance from the interface cementite/ferrite $[\mu \mathrm{m}]$

Figure $2 c$

$83 \times 61 \mathrm{~mm}(600 \times 600 \mathrm{DPI})$ 


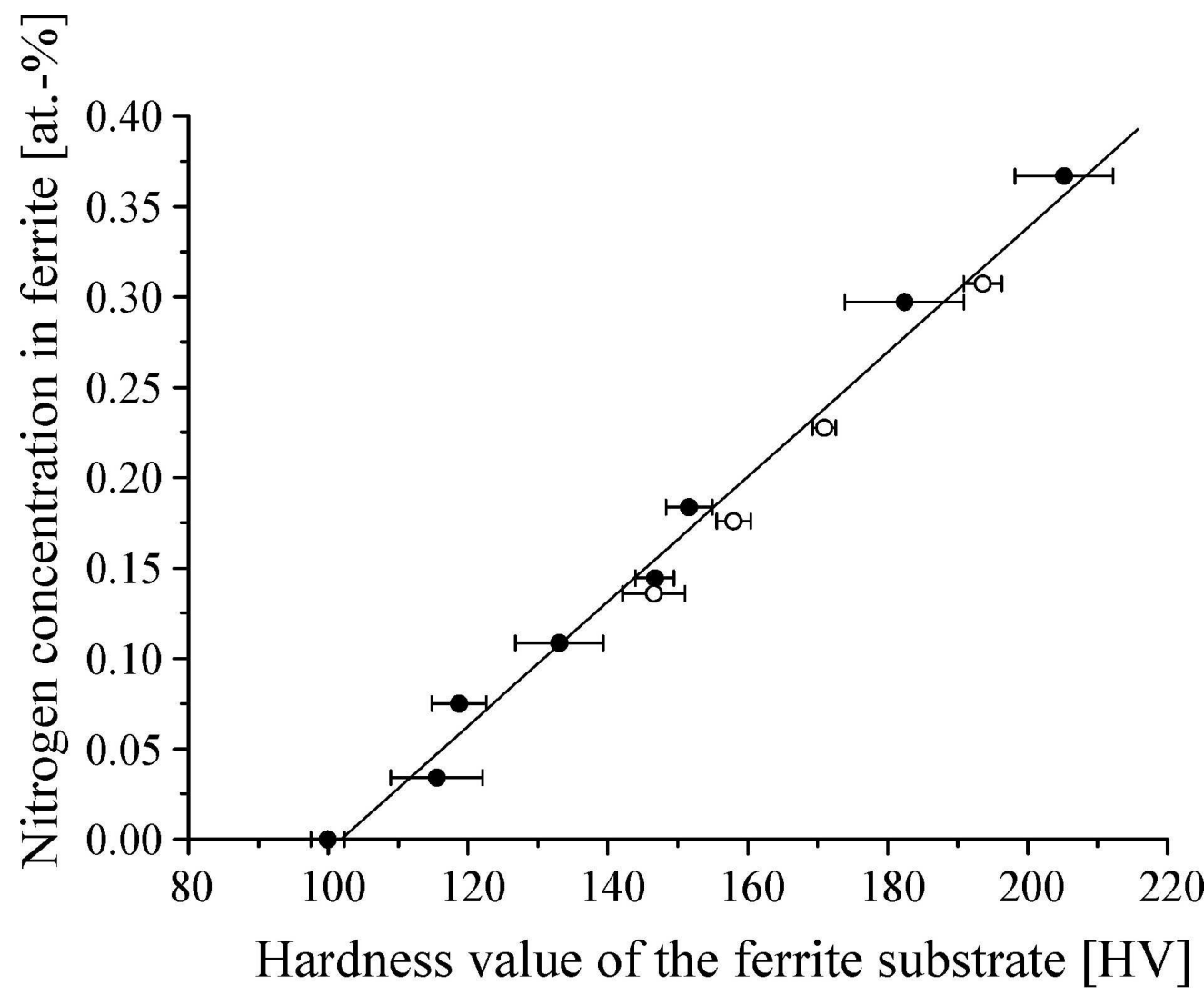

Figure 3

$79 \times 65 \mathrm{~mm}(600 \times 600 \mathrm{DPI})$ 


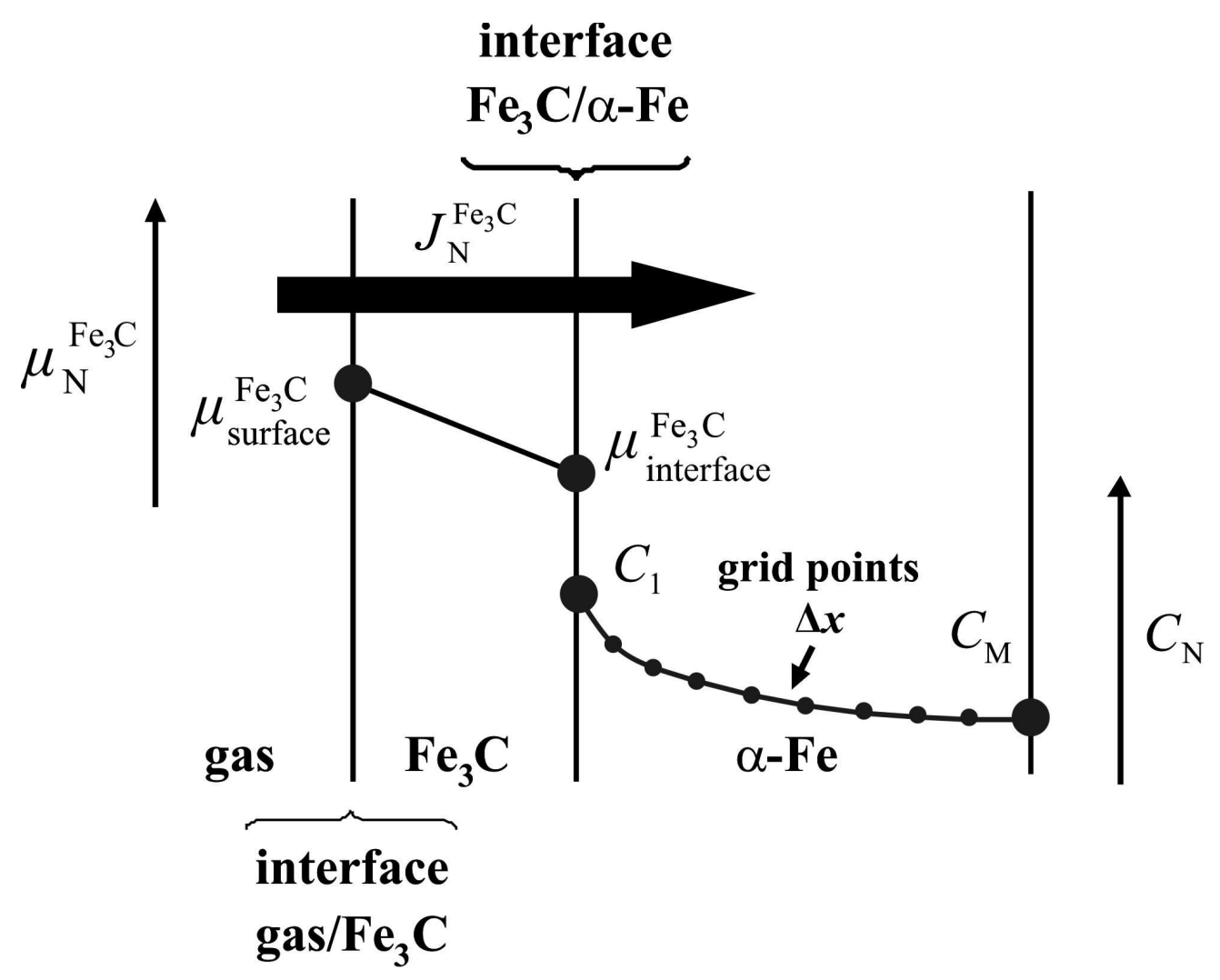

Figure 4

$83 \times 67 \mathrm{~mm}(600 \times 600 \mathrm{DPI})$ 


1
2
3
4
5
6
7
8
9
10
11
12
13
14
15
16
17
18
19
20
21
22
23
24
25
26
27
28
29
30
31
32
33
34
35
36
37
38
39
40
41
42
43
40
45
49
50
51
52
53
55
50

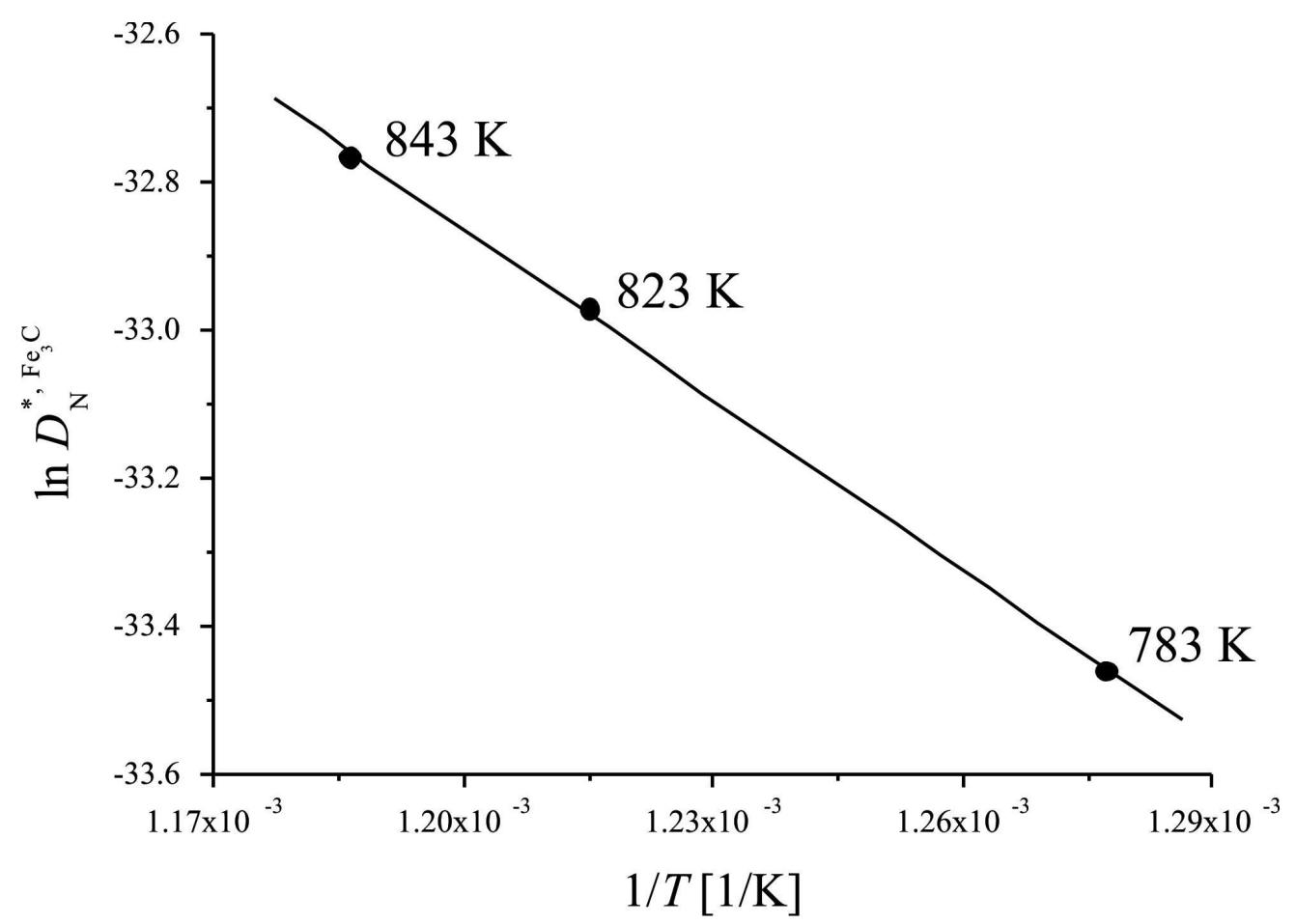

Figure 5

$83 \times 59 \mathrm{~mm}(600 \times 600$ DPI $)$ 